\title{
Quiero ser citado
}

\section{Leonardo Romero}

Editor Jefe, Instituto de Investigación de Ciencias Biológicas Antonio Raimondi, Facultad de Ciencias Biológicas, Universidad Nacional Mayor de San Marcos. Apartado 11-0058, Lima 11, Perú. Email: Iromeroc@unmsm.edu.pe

Publicado impreso: 29/01/2011

Publicado online: $21 / 01 / 2011$

Después de varios ańos de ser editor, muchos de mis jefes confunden la revista con el editor, y es común oír cosas como "conferencia a cargo de la revista" o en conversaciones se dirijan a mí para decir "y porque no te citan”, refiriéndose al motivo porqué la Rev peru biol. no es citada por otros trabajos. Aprovechando ese desquicio, en los siguientes párrafos encarnare a la revista y al editor, en la fusión mágica en la que algunos de mis jefes me imaginan.

\section{¿Alguien me cita?}

Desde hace varios años intentamos interpretar nuestra situación como revista, plantear objetivos y ser más eficientes. Escribimos sobre la calidad de los contenidos ${ }^{1}$; inventamos conceptos como el "anfimercado" para explicar el porqué de las exigencias ${ }^{2}$, argumentamos la relación de una revista científica con la ciencia y la sociedad ${ }^{3}$; resaltamos la importancia de la biodiversidad como tema ${ }^{4}$; analizamos la maraña de conceptos politicológicos de CTyI, desarrollo sustentable y ciencia, todos confundidos en una torre de babel de oscuras lenguas movidas por la ignorancia y conveniencia 5 . También tratamos de recurrir a la comunidad científica como un soporte para nuestro desarrollo o cómo pensamos sobrevivir ${ }^{6}$ y reflexionamos sobre la realidad del Perú 7 . Personas imaginarias nos preguntaron con las miradas y entre las líneas del email que nos enviaban, y respondimos tratando de interpretar buscando alguna solución ${ }^{8}$. Por último, hemos querido sentirnos bien y nos dimos aliento comparando lo que éramos con lo que somos? ${ }^{9}$. Todos estos escritos fueron momentos, con las intenciones de sentirnos conscientes, explicando lo que vemos y tomando decisiones para tratar de mejorar, pero todas esas conversaciones nos deslumbraron cuando fueron correctas o tenían visos de serlo, y a la vez fueron el velo de algo que no percibimos al inicio, o lo percibimos pero no tomamos conciencia que estaba ahí.

¿Quién lee nuestras páginas, cuántos la leen, cuántos usan el contenido de la revista? Son esas las preguntas que no nos hicimos y que quedaban veladas por el hecho de haber avanzado algo en nuestro crecimiento. Pero llegar a respuestas objetivas puede ser muy difícil, porque la información no es tan fácil de acceder, o simplemente porque no existe.

En un trabajo científico, la cita es la forma como el autor refrenda su afirmación en otro u otros trabajos a los que el lector puede acudir para investigar o comprobar lo tratado en el artículo. Pero, para que ocurra esta citación, varias cosas deben haber sucedido. La revista debe estar accesible, en la biblioteca o por INTERNET, debe ser fácil de ubicar, algo así como escribir y presionar un botón. Para llegar a ese momento, muchos procesos, y cosas deben de haber pasado; mucho esfuerzo, tiempo y dinero deben haber sido invertidos, casi siempre todo pasa desapercibido.

Explorando la base de datos $S c o p u s^{10}$, podemos buscar los artículos que han citado algún trabajo publicado en la Rev peru biol. y tratar de describir lo que ha sucedido en los últimos años. Aunque la Rev peru biol. salió a la luz en 1974, recién a partir de 1998 comenzó una vida continua, y después del año 2005 inició un incremento continuo de citas hasta el año 2010. Entre los años 1996 y 2010, en Scopus se registran 273 artículos

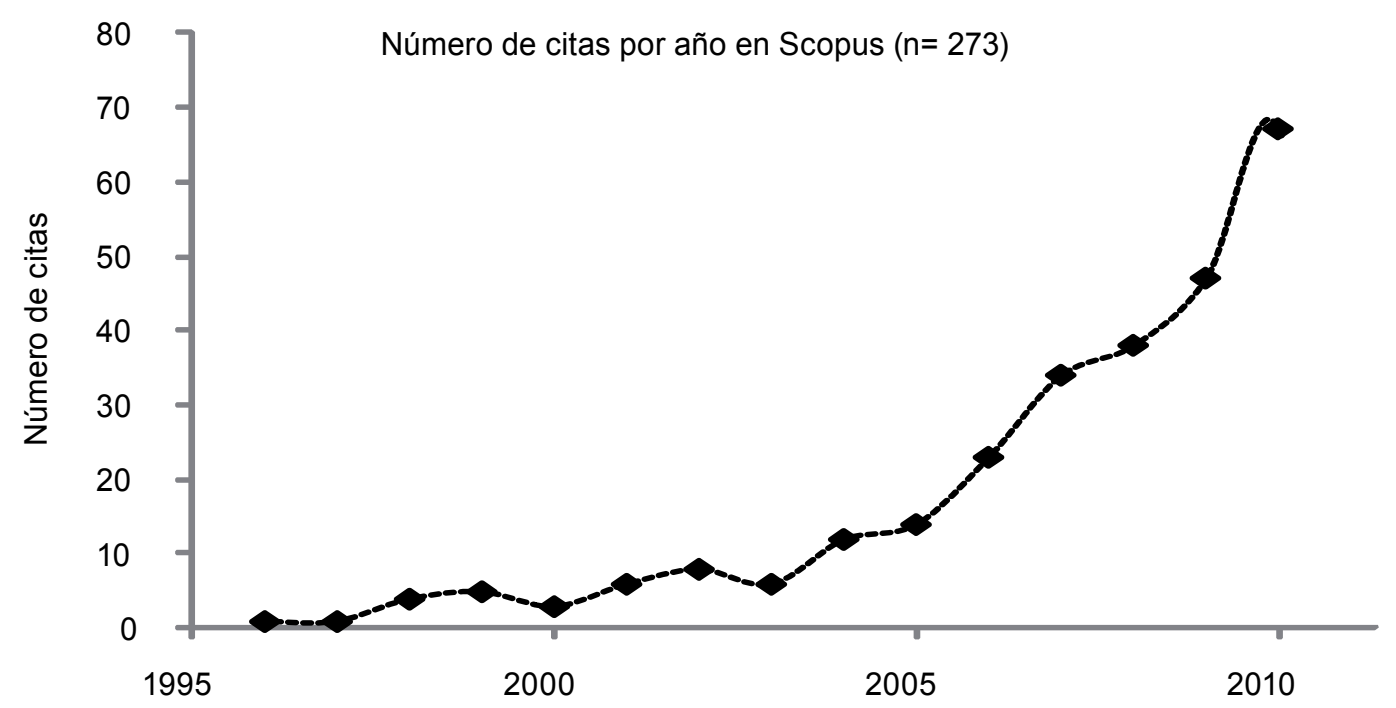

Número de citas de trabajos publicados en la Rev peru biol por año en revistas indizadas en la base de datos Scopus. Después del año 1998 la Rev peru biol, adquiere continuidad, incrementa constantemente el número de artículos, la variedad de autores, las instituciones que participan, los artículos en ingles, su distribución y visibilidad. 
que citan entre 1 y 4 veces la Rev peru biol. periodo en el que se habíamos publicado casi 550 artículos. Entre el año 2009 y 2010 encontramos 130 citas, el 47,6\% de las citas de todo el periodo 1996 - 2010; estas 130 citas son de 91 artículos de la Rev peru biol., lo que representan aproximadamente el 16\% de todos los trabajos publicados desde 1998.

\section{¿Quién me quiere citar?}

Si analizamos las citas de los años 2009 al 2010, observamos años en que los artículos publicados tienden a ser más citados, fenómeno que recuerda a un perfil andino. Los artículos publicados el 2003, 2005 y 2007 son más citados, lo que puede ocurrir por lo amplio de la temática de la Rev peru biol. y la falta de mecanismos de difusión para ciertos temas.

Scopus clasifica a sus revistas en áreas y podemos tener información sobre cómo las citas de la Rev peru biol. se distribuyen en ellas. Debemos tener presente que una revista puede ser clasificada en una o más categorías por lo que las citas pueden duplicarse, por lo que usar el porcentaje de citas sería una opción adecuada. Agricultural and Biological Sciences, Environmental Science y Earth and Planetary Sciences acumulan el 68\% de las citas, estas áreas corresponderían principalmente a las nuestras de biodiversidad y ecología, mientras que las de Immunology and Microbiology, Biochemistry, Genetics and Molecular Biology, Medicine, Social Sciences, Pharmacology, Toxicology and Pharmaceutics, Veterinary y Otras corresponderían principalmente a nuestras áreas de biotecnología y biomédicas. Dos temas son necesarios discernir, uno es el de entobiología principalmente botánica cuyos artículos son citados en temas sociales, de medicina y farmacia, y otro es el de taxonomía de parásitos, citados en temas de medicina y veterinaria.

Hemos podido registrar 89 títulos de revistas que nos citan entre el año 2009 y 2010. Entre 5 y tres citas en orden decreciente están Zootaxa, Journal of Ethnopharmacology, American Museum Novitates, Revista de Biología Marina y Oceanografía, Zoologica Scripta, Applied Microbiology and Biotechnology, Bioresource Technology, Neotropical Entomology, estas acumulan el $39 \%$ de las citas del periodo 2009 - 2010. Un aspecto que parece resaltar en esta variedad de títulos es el tipo de información que proporciona la Rev peru biol.; descripciones de nuevas especies, reportes de especies, listas de especies, especies endémicas, son la información más citada y útil para otros investigadores y que pueden encontrar en la Rev peru biol.

\section{Qué hacer para que me citen}

La única forma para que nos citen es que conozcan lo bueno que es nuestro trabajo y nos lean. Para eso, nosotros nos podemos citar y publicar (auto-cita, por ejemplo yo me cite 9 veces en este editorial, lástima que no será indizado); que es algo saludable si se realiza correctamente. Otra forma es trabajar en equipo con otros investigadores y que ellos nos citen, lo cual es importante, recomendable y lo más frecuente. Por último, como investigador podemos enviar nuestro trabajo a alguna de las revistas de alto factor de impacto (muy citada) con la esperanza que de todas maneras alguien por ahí nos cite influenciado por el prestigio de la revista. Para que me citen más, como revista tenemos que indexarnos en bases de datos y buscadores, distribuirnos en diferentes medios de comunicación, tradicionales (impresos, online), sofisticados (ebook) y de vanguardia (twiter, facebook, blogs, y los que vendrán), y lograr adquirir visibilidad e importancia en la comunidad científica.

Con un poco más de trabajo, podemos buscar en la base de datos de Scopus a los autores de los 273 artículos que citan a la Rev peru biol. en el periodo 1996 - 2010, en busca de posibles autores que se auto-citen. Incluimos a cualquier autor que haya publicado en la Rev peru biol., o miembro de Comité consultivo o Editor. Encontramos que solamente 56 de los 273 (20,5\%) aparecen como autor del artículo donde ocurre la cita; casi todos en realidad están en el periodo entre 2007 y 2010 . Esto quiere decir que la alternativa de que las citas dependen de la labor de visibilidad de la revista estaría jugando un importante papel en la cantidad de citas.

Entonces ¿Qué hacer para que me citen? Además de esforzarnos más para tener mejor información que publicar, tenemos que prepararnos para las nuevas necesidades, que como investigadores a su vez son nuestras exigencias. Tener la información arrastrando

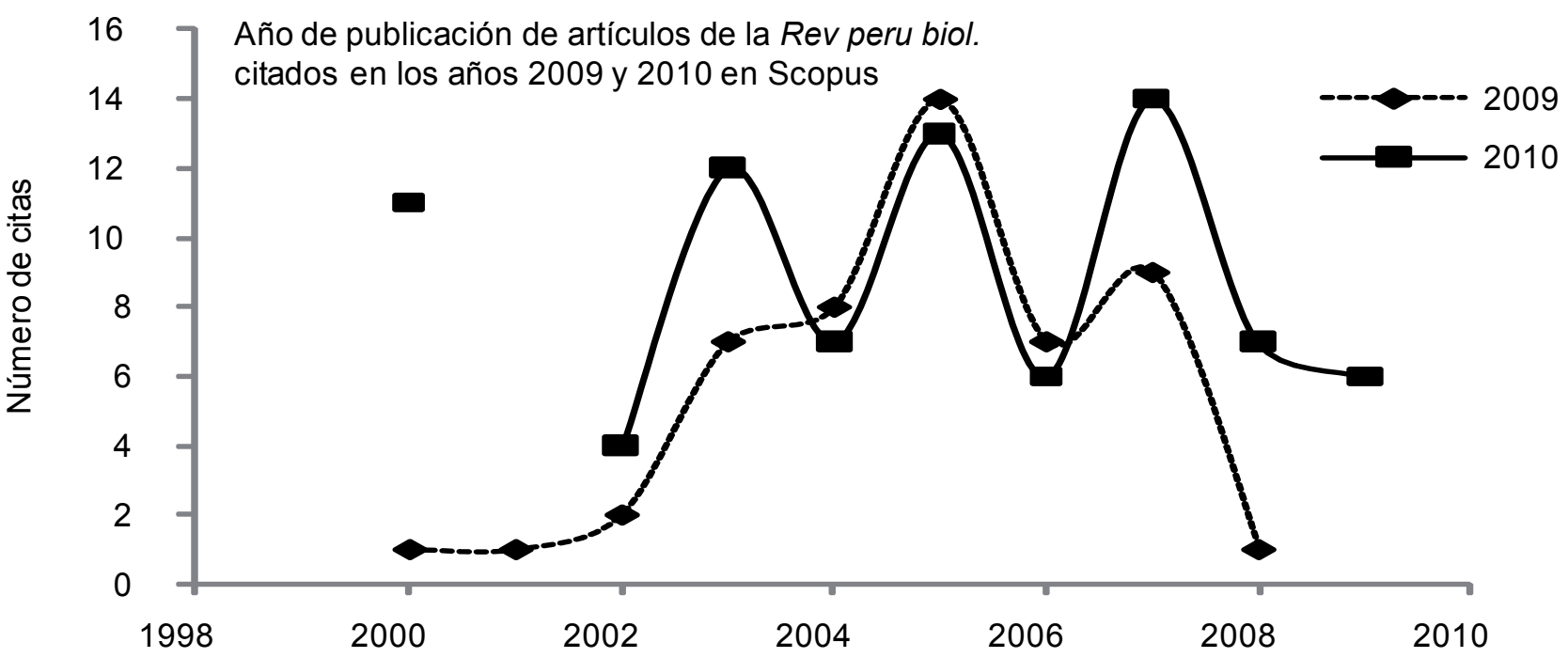

Análisis de las citas que recibe la Rev peru biol en los años 2009 y 2010 en las revistas indizadas en la base de datos Scopus. Ambos años coinciden en que los artículos del año 2005 son más citados. En el año 2010 artículos anteriores a 1998 son citados hasta 11 veces. 
Porcentaje de citas por áreas según clasificación de Scopus desde 1998 al 2011

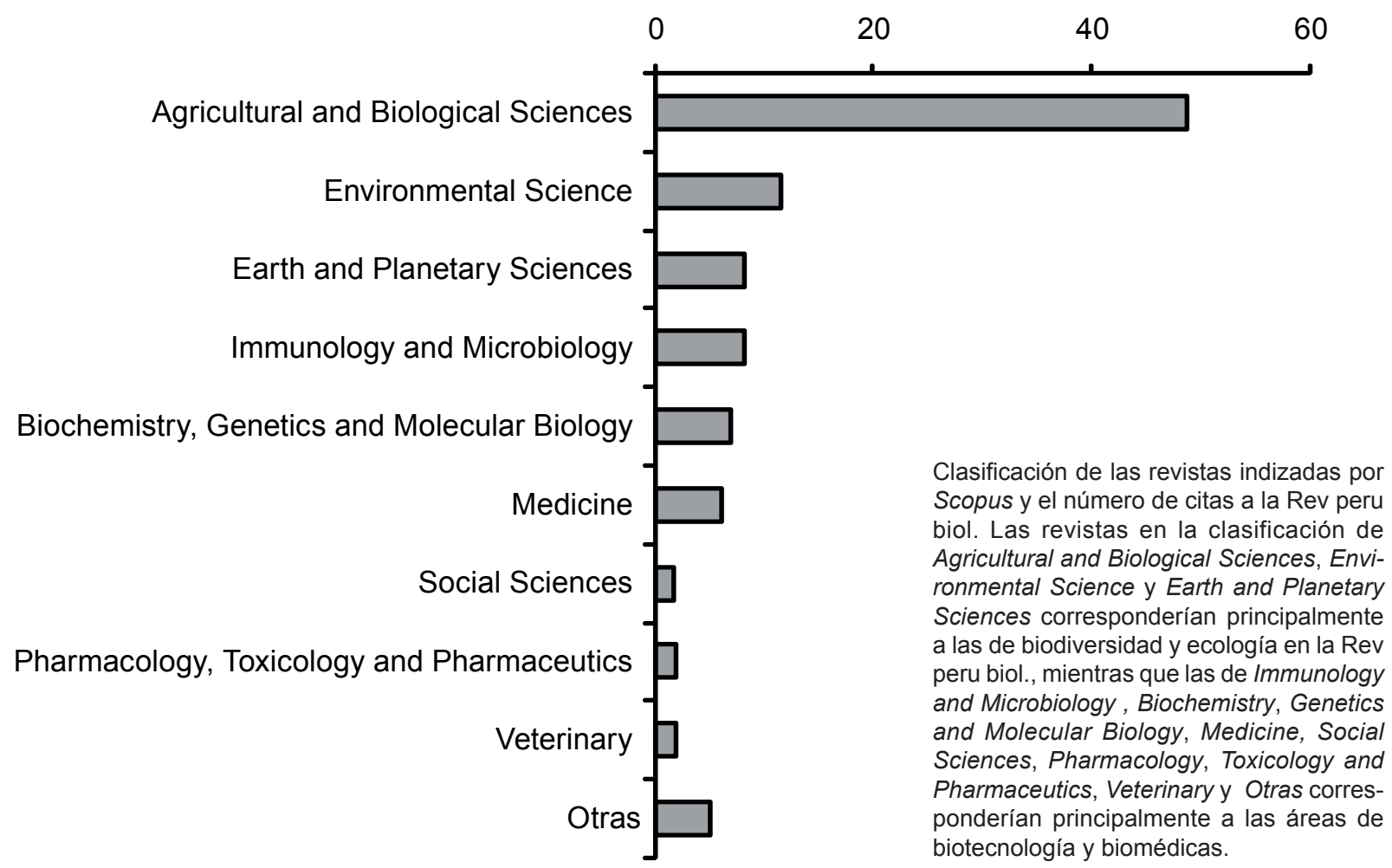

nuestro dedo sobre un touch pad cuando estamos en el campo, o que aparezca en Google Earth cuando lo consultamos a través de nuestro iphone, leerlo en un ebook cuando vamos al trabajo, subirlo a una red social, a un banco de datos o asegurarnos de ser los primeros en algo y decirlo cuanto antes; para toda esas vertiginosas necesidades los autores y las revistas tenemos que aportar, en nuestro caso trabajar más desde los cimientos de nuestra investigación.

\section{Si lo hago ¿me citaran?}

"Run for your lives! End of the World!" - Electronic publication of new plant names es el título con el que Sandra Knapp et al. ${ }^{1{ }^{1}}$ nos presenta varios problemas en las publicaciones referidas a taxonomía, nuevos registros y distribución. Afecta a las conocidas como check list, publicaciones que hace una década las revistas prestigiosa no aceptaban, o no daban cabida, mientras que esa información era, y es cada vez mas requerida por la sociedad.

En la actualidad algunas revistas ya han afrontado el reto de publicar esa información que fue despreciada por no constituir investigaciones o un seminal paper. Notable ejemplo son las revistas Check List (http://www.checklist.org.br/index), ZooKeys (http://pensoftonline.net/zookeys/index.php/journal/index), PhytoKeys (http://www.pensoft.net/journals/phytokeys/). Todas ellas dedicadas a la misión de poner en orden la información taxonómica, hacerla accesible y disponible tan rápidamente como sea posible o soñable (en el universo de posible lo imposible tiene su lugar). Todos esos objetivos con la finalidad de coadyuvar a la toma de decisiones para la conservación de la biodiversidad. Mientras tanto, otras revistas se han ido adecuando de una u otra manera a esos reclamos.

También es exigencia en las normas de las revistas ${ }^{12}$ brindar toda la información que pudiera ayudar a discutir y refrendar el trabajo expuesto en el artículo. Así, las revistas alojan bases de datos paralelas y archivos extras al artículo, y son exigencias que las imágenes, material biológico y la información deban ser depositados en repositorios públicos (como museos, en el caso de colectas o bases de datos como el GenBank o el Entrez Gene) e indicar los códigos o vouchers respectivos; algo que nosotros hace algún tiempo denominamos trazabilidad ${ }^{13}$.

La información que se presenta debe tener un orden y está dado entre otros por los esquemas XML (en su mayoría) que permiten el aprovechamiento de la información organizándola en forma de metadatos o simplemente en protocolos de transferencia de la información. Un esfuerzo bastante aceptado es el Darwin Core (DwC, http://rs.tdwg.org/dwc/index.htm) que permite la asociación de información geográfica y biológica que puede ser fácilmente procesado.

Sandra Knapp et al. también señalan los tiempos de publicación como factores importantes para tomar en cuenta en la elección de revistas que se adecuen a la necesidad de publicaciones de taxonomía y sistemática. De inicio, las que presentan publicación impresa en papel ya tienen demora, sin embargo la preocupación de Sandra Knapp et al. es más porque aun hay reticencia en los miembros de la comunidad para aceptar las publicaciones online de especies nuevas. Una solución propuesta sería un registro de especies nuevas; algo que no es novedoso en botánica (International Plant Names Index (IPNI), http:// www.ipni.org/) y que se está llevando a la práctica en zoología (ZooBank, http://zoobank.org/). Los códigos que relacionen toda la información sobre los nombres de las especies, los creadores, los documentos de creación e información adicional son la expresión de complejos sistemas, que necesitan el consenso de la comunidad de investigadores para que sean exitoso; es más creemos que solo hay una alternativa, el éxito y por lo tanto el 
consenso. El consenso de la comunidad será desde los niveles de colecta, para que los protocolos de información sean completos y el producto (la información) tenga la calidad necesaria; podríamos decir que con información colectada con esa rigurosidad estaremos más cerca de ser citados.

Por otro lado, una buena noticia a fines del año 2010 fue la inclusión de la Rev peru biol. en la Red de Revistas Cientificas de América Latina y el Caribe, España y Portugal, Sistema de Información Cientifica Redalyc o simplemente Redalyc ${ }^{14}$; un sistema impulsado por la Universidad Autónoma de Estado de México. Este sistema va más allá de un simple repositorio; integra tecnología que permite dar mayor visibilidad a las revistas que integran su acervo. Muchas revistas que se han integrado a Redalyc han incrementado el número de citaciones gracias a la capacidad de Redalyc de conectarse con redes académicas. Con el tiempo Redalyc incluirá toda la producción de la $\mathbf{R e v}$ peru biol. convirtiéndose en un referente de la versión online, por lo que estamos incluyendo el protal de Redalyc como un URL para la divulgación de nuestros artículos. Además, este sistema se retroalimenta con la información que proporciona y presenta un análisis de citas, de lecturas, bibliométricas y de relaciones (de colaboración) entre autores, servicios que permiten el análisis de la actividad científica y editorial, lo cual redunda en el mejor funcionamiento y calidad de las revistas. Redalyc se suma a otras bases de datos como Periódica, LIPECS, Zoological Record, Scielo, BIOSIS Previews y Biological Abstracts donde la Rev peru biol. esta indizada y que le permiten dar visibilidad a sus artículos, acercándonos también a la deseada meta de ser más citados.
1 Romero L. 2003. La calidad y el rol de las Revistas Científicas. Rev peru biol. 10(1): 3 - 4

2 Romero L. 2005. Pinitos de una publicación científica en un escenario de mercados. Rev peru biol. 12(1): 3-4

3 Romero L. 2005. Divulgación científica y la biodiversidad. Rev peru biol. 12(2): 182

4 Romero L. 2005. El difícil mercado de una necesaria publicación científica. Rev peru biol. 12(3): 339-340

5 Kahn F. 2007. Ciencias empíricas, ética y desarrollo sostenible. Rev peru biol. 13(3): 151- 154

6 Romero L. 2008. Las comunidades y sus revistas científicas. Rev peru biol. 15(supl. 1): 003- 004

7 Romero L. 2009. Un poco de la realidad del Perú. Rev peru biol. 15(2): 006

8 Romero L. 2009. Respondiendo preguntas. Rev peru biol. 16(1): 003- 004

9 Romero L. 2009. Los 35 años de la Revista Peruana de Biología. Rev. peru. biol. 16(2): 145 - 146

$10 \mathrm{http} / / /$ www.scopus.com/home.url

11 Sandra Knapp et al. 2010. "Run for your lives! End of the World!" - Electronic publication of new plant names. TAXON 59 (4): 1009-1010

12 Revisar los requerimientos de PLoSOne (http://www.plosone. org/static/guidelines.action\#requirements)

13 Romero L. 2007. Trazabilidad una característica para un artículo científico. Rev. peru. biol. 14(1): 003- 004

$14 \mathrm{http} / / /$ redalyc.uaemex.mx/ 